\title{
Intimate partner violence during pregnancy and risk of still birth in hospitals of Tigray region Ethiopia
}

\author{
Kahsay Zenebe Gebreslasie*, Solomon Weldemariam, Gelawdiyos Gebre and Mihret-Ab Mehari
}

\begin{abstract}
Background: Pregnancy may represent a time of exceptional vulnerability to intimate partner violence because of changes in women's conditions. Despite the fact that intimate partner violence during pregnancy confers considerable risk to the health of the woman and her fetus, data regarding to association of stillbirth and intimate partner violence is lacking in Tigray region. The objective of this study is to assess intimate partner violence during pregnancy and its association with still birth among postpartum mothers in hospitals in Tigray Region of Ethiopia.

Methods: Cross-sectional study design was used to assess 648 women about intimate partner violence during pregnancy and its association with still birth. Simple random sampling technique was employed to select health facilities and systematic sampling was used to select the study participants. Data was entered by using Epi info version 3.5.1 and analyzed using SPSS version 20. Logistic regression analysis was done to assess the association between exposure to intimate partner violence during pregnancy and stillbirth while adjusting for possible confounders.

Results: The prevalence of still birth was 3.6\%in this study population. There was a statistically significant association between exposure to intimate partner violence during pregnancy and still birth. Pregnant women who were exposed to intimate partner violence during pregnancy were three times more likely to have still birth 3.3(95\% Cl: 1.1-9.7) as compared to those who were not exposed. Another important factor associated with stillbirth was low birthweight $16.7(95 \% \mathrm{Cl}, 6-46)$.
\end{abstract}

Conclusions: The prevalence of still birth in this study was high. Women who subjected to intimate partner violence during pregnancy had greater risk of having stillbirth baby.

Keywords: Intimate partner, Violence, Pregnancy, Still birth

\section{Background}

Intimate partner Violence (IPV) is defined as a psychological, sexual and physical harm by a current or former partner [1]. Intimate partner violence is a public health problem at national and global level $[2,3]$. IPV has wide reaching negative impact on a woman's autonomy, self-esteem, ability care for her family and her ability participate in social activities $[4,5]$.

\footnotetext{
* Correspondence: kahsay14z@gmail.com
}

Mekelle University, College of Health Science, Mek'ele, Ethiopia
A multi-country study by the World Health Organization shows that 15 to $71 \%$ of women experience physical and/or sexual in their lifetime [6]. Domestic violence is a common and tolerated practice in both urban and rural part of Ethiopia. An Ethiopian study elucidated that nearly three out of four $(71 \%)$ women are subjected to IPV in their lifetime [7].

The prevalence of IPV among pregnant mothers ranged from $13.5 \%$ in Uganda to $2 \%$ in Australia [8]. Study from multi country also shown the prevalence of IPV during pregnancy was range from 1 to $28 \%$ [5]. In

C C The Author(s). 2020 Open Access This article is licensed under a Creative Commons Attribution 4.0 International License, which permits use, sharing, adaptation, distribution and reproduction in any medium or format, as long as you give appropriate credit to the original author(s) and the source, provide a link to the Creative Commons licence, and indicate if changes were made. The images or other third party material in this article are included in the article's Creative Commons licence, unless indicated otherwise in a credit line to the material. If material is not included in the article's Creative Commons licence and your intended use is not permitted by statutory regulation or exceeds the permitted use, you will need to obtain permission directly from the copyright holder. To view a copy of this licence, visit http://creativecommons.org/licenses/by/4.0/ The Creative Commons Public Domain Dedication waiver (http://creativecommons.org/publicdomain/zero/1.0/) applies to the data made available in this article, unless otherwise stated in a credit line to the data. 
addition to this, a systemic review of research conducted in various African countries indicated that the overall prevalence of intimate partner violence during pregnancy ranges from 2.3 to $57.1 \%$ [9].

In Ethiopia, IPV during pregnancy was found to range from $4 \%$ (merely physical violence) to $8 \%$ (all forms of IPV) $[7,10]$. Study from Northwest Ethiopia revealed that the occurrence of IPV during pregnancy was $25.4 \%$ [5].

According to Ethiopia's demographic health Survey data in 2016, perinatal mortality rate was 33 per 1000 pregnancies [10].

According to 2014 new born action plan global multi partner movement to end preventable still birth, the target was set to reduce the magnitude of stillbirth to less than 12 per 1000 births[(11]. A study undertaken in 157 countries revealed that the estimated stillbirth rate was 18.4/1000 births. Of the 2.6 million stillborn babies delivered in 2015, 98\% occurred in low and middle income countries [11].

The risk of IPV is high among women of reproductive age and this is mainly attributed to changes in physical, social, emotional or financial status during pregnancy. Pregnancy puts a woman at greater vulnerability to intimate partner violence [12]. Consequently, IPV during pregnancy worsens maternal condition and predisposes to adverse fetal and neonatal outcomes [13, 14]. Some existing research indicates that there may be a statistically significant association of IPV during pregnancy and stillbirth $[3,15]$. This might be due to the impact of IPV on a women's life style, physical and psychological health [16]. Some studies however do not show an association between IPV violence and stillbirth [7]. This may be less about lack of association and more about grave underreporting of IPV in Africa.

In Ethiopia, particularly in study area, there are no studies looking at the association between IPV during pregnancy and stillbirth. Therefore, this study aims to bridge this gap.

\section{Methods}

\section{Study setting}

The Tigray region is located $783 \mathrm{~km}$ away from Addis Ababa, capital city of Ethiopia. According to 2007 census, the population of Tigray region was estimated to be $4,316,988$. Women of child bearing age (15-49) comprise 251,650 of the population. According to $2015 \mathrm{Ti}$ gray regional health bureau annual report, there are a total of one specialized referral hospital, 15 general hospitals, 22 primary hospitals, 204 health centers and 712 health posts and three private hospitals. There are 51 doctors with specialty training in obstetrics and gynecology, 87 general practitioners, 3092 nurses and 792 midwives in the region. The study was conducted from November 2017-June 2018. Institutional based cross-sectional study was used.

\section{Sample}

The study population was all women who gave birth in hospitals within the Tigray region. Women who are unable to hear were excluded from the study.

There are 41 hospitals (1 specialized hospital, 15 general hospitals, 22 primary hospitals and 3 private hospitals) which provide delivery service in the study area. Health facilities were stratified in to private and public hospitals. For the purposes of this study, one private hospital and eight public hospitals were selected by simple random sampling technique. Participants from each selected health facilities were sampled by systematically. Every 3rd postpartum women were included until the required sample size was reached. Consecutive participant was included if the selected participant was not eligible. Average client load for each hospital was assessed using the patient flow three months' prior to data collection period and proportional allocation to each hospital was made based on their respective quarterly client flow.

To calculate the sample size, we used available data that indicates $25.8 \%$ prevalence of IPV during pregnancy in Ethiopia [14] and 95\% confidence interval, 5\%margin of error, design effect 2 and expected non response rate $10 \%$. Based on this, the calculated sample size was 648 .

Data on socio-demographic characteristics of participants (age, residence, religion, educational status, marital status and occupational status) and obstetrics characteristic (mode of delivery, PROM, hypertension, APH, ANC, follow up, apgar score, preterm birth, low birth weight and whether the was desired pregnancy/not) were collected through interviews and chart view.

\section{Instrument}

Data was collected using a structured questionnaire that was administered to post-partum women by trained staff. Staff involved in administering the questionnaires included nine midwives (diploma level training) who were supervised four Midwives (bachelor level training). Training was given to both data collectors and supervisors about the aim of the study, procedures, how to approach the study participants and data collection techniques.

\section{Intimate partner violence}

Maternal exposure to IPV was determined through the question: "when you were pregnant with this child, did your current partner or boyfriend do any of the following things to you? The lists of potential offences were as follows: Physical violence: slapped, pushed or shoved, hit with fist or something else that could hurt her, trauma to the abdomen, choked or burnt on purpose, used or 
threatened to use knife, gun or weapon. Emotional violence: insult, humiliation, intimidation on purpose, verbal threats. Sexual violence: Forced into sexual intercourse when you did not want, had sexual intercourse when you did not want to because you were afraid of what partner might do, forced to do something sexual that you found degrading or humiliating. Stillbirth: is typically defined as fetal death at or after 28 weeks of pregnancy. It results in a baby born without signs of life.

\section{Procedure}

Questionnaire was prepared first in English and then translated into Tigrigna and back translated to English by language expert to ensure the accuracy of the information.

Data on still birth was collected from the medical charts and direct interviews via questionnaires. Outcomes of interest for this analysis pertained directly to neonatal outcomes and were obtained through chart review within $72 \mathrm{~h}$ of delivery. Birth weight (g) and gestational age (weeks) were taken directly from the chart. Low birth weight was assigned if the neonate weighed $<2500 \mathrm{~g}$, and preterm birth was considered if the neonate was born at $<37$ completed weeks of gestation and $>28$ weeks. Gestational age was computed (dated) from either first trimester ultrasound or reliable last menstrual period.

An ethical approval for the study was obtained from Mekelle University College of health science health research ethics review committee. Permission letter was obtained from regional health office and was presented to selected hospitals. Written consent was taken from each participant before the starting of data collection and for those women who are under age, written consent was obtained from their parent. Since IPV is sensitive issue the interviews were conducted in a private room. Confidentiality was maintained throughout the study. In addition, participants were told that they have the right not to participate and/or could withdraw from the study at any point.

\section{Data process and analysis}

Double data entry was done by using Epi info version 3.5.1 and exported to SPSS version 20 software package for analysis. Experience of any physical, sexual or emotional violence was considered if a woman reported being exposed to at least one of the acts of violence exerted by her partner while she was a pregnant for current neonate.

To estimate the association between maternal exposure to intimate partner violence and risk of still birth, logistic regression analyses were performed and odds ratios (OR) with 95\% confidence intervals (CI) were calculated. Multivariable logistic regression analysis was performed where intimate partner violence plus other covariates that could influence still birth such as age, educational level, occupation during pregnancy and alcohol intake etc. The degree of association between independent and dependent variables were assessed using odds ratio with $95 \%$ confidence interval.

\section{Results}

\section{Socio-demographic characteristics}

A total of 647 participants took part in this study with a response rate of $99.8 \%$.Out of the total respondents, 458 $(70.78 \%)$ of them were urban residents. The mean age of the respondents was $27 \pm 6$ years. Majority of respondents 530(81.9\%), were between ages $20-35$ years old although a few were younger. Most participants were married $(N=610 ; 94.28 \%)$ were married. Out of the participants, nearly half were housewives $(N=301$; 46.5\%) (Table 1).

\section{Obstetrics characteristics of the participants}

A quarter of the women $(N=155 ; 24 \%)$ delivered via cesarean section. Similarly, a quarter of the women (25\%) experienced premature rupture of membrane, 66 (10.2\%) experienced hypertension and 35 (5.4\%) had antepartum hemorrhage (APH). Among these participants, 611(94.4\%) had at least one antenatal care (ANC) follow up during their last pregnancy. In this study

Table 1 Socio-Demographic characteristics of respondents, Tigray, North, Ethiopia, 2018

\begin{tabular}{|c|c|c|c|}
\hline Variable & & Frequency & Percent \\
\hline \multirow[t]{2}{*}{ Residence } & Urban & 458 & 70.78 \\
\hline & Rural & 189 & 29.22 \\
\hline \multirow[t]{3}{*}{ Age } & $\leq 19$ & 50 & 7.7 \\
\hline & $20-34$ & 530 & 82 \\
\hline & $\geq 35$ & 67 & 10.3 \\
\hline \multirow[t]{2}{*}{ Religion } & Orthodox & 581 & 89.8 \\
\hline & Muslim & 66 & 10.2 \\
\hline \multirow{5}{*}{$\begin{array}{l}\text { Educational } \\
\text { Status }\end{array}$} & Unable to read \&write & 108 & 16.7 \\
\hline & Read and write & 44 & 6.8 \\
\hline & Primary education & 175 & 27 \\
\hline & $\begin{array}{l}\text { Secondary education } \\
\text { and college }\end{array}$ & 211 & 32.6 \\
\hline & Diploma and above & 109 & 16.8 \\
\hline \multirow[t]{2}{*}{ Marital Status } & Married & 610 & 94.3 \\
\hline & Single & 37 & 5.7 \\
\hline \multirow{6}{*}{$\begin{array}{l}\text { Occupational } \\
\text { status }\end{array}$} & Housewife & 301 & 46.5 \\
\hline & Merchant & 71 & 11 \\
\hline & Farmer & 127 & 19.6 \\
\hline & Private employee & 42 & 6.5 \\
\hline & Governmental employee & 95 & 14.7 \\
\hline & Others & 11 & 1.7 \\
\hline
\end{tabular}


Table 2 Obstetrics characteristics of respondents, Tigray, North, Ethiopia, 2018

\begin{tabular}{llll}
\hline Variable & & Frequency & Percentage \\
\hline Mode of delivery & Vaginal & 492 & 76 \\
PROM & C/S & 155 & 24 \\
& Yes & 162 & 25 \\
Hypertension & No & 485 & 75 \\
& Yes & 66 & 10.2 \\
APH & No & 581 & 89.8 \\
& Yes & 35 & 5.4 \\
ANC follow up & No & 612 & 94.6 \\
& Yes & 611 & 94.4 \\
Still birth & No & 36 & 5.6 \\
Pregnancy wanted & Yes & 23 & 3.6 \\
& No & 624 & 96.4 \\
Preterm delivery & No & 605 & 93.5 \\
& Yes & 42 & 6.5 \\
Low birth weight & No & 570 & 10.8 \\
& Yes & 120 & 89.2 \\
& No & 527 & 18.5 \\
\hline
\end{tabular}

population, $42(6.5 \%)$ of the women admitted that their index pregnancy was unwanted. Data on pregnancy outcome shows that $70(10.8 \%)$ women delivered before reaching term and 120 (18.5) babies were low birth weight. The magnitude of still birth in this study was 23 (3.6\%) (Table 2).

\section{Substance use}

Of the total participants, 288 (44.5\%) women admitted that they ingested alcohol during pregnancy sometimes and $10(1.6 \%)$ ingested chat (a stimulant leaf) while they were pregnant with the index neonate. Three $(0.5 \%)$ women smoked while pregnant.

\section{Types of intimate partner violence}

Around 47 (7.3\%) women experienced intimate partner violence during their index pregnancy in which 22 of them were subjected to physical violence, 39 of them experienced sexual violence and the remaining 8 women were subjected to psychological violence.

\section{Factors associated with still birth}

In our study, women who were subjected to intimate partner violence during pregnancy are 3.3 times $(\mathrm{AOR}=$ 3.3; 95\% CI: 1.1-9.7) more likely to have stillborn baby than who did not experience IPV during pregnancy.

Low birth weight was also significantly associated with still birth. Babies with low birth weight have 16.7 times $(\mathrm{AOR}=16.7 ;$ 95\% CI:6-46) risk of still birth as compared with babies' weight greater than or equal to $2.5 \mathrm{~kg}$. Having unwanted pregnancy and preterm birth were significant associated with still birth in bivariate analysis but is has no association in multivariate analysis (Table 3).

\section{Discussion}

This study which assessed the association between IPV during pregnancy and stillbirth provided new and important information that has been missing from research in low income countries like Ethiopia. The magnitude of intimate partner violence during pregnancy is concerning and can have important implications on neonatal outcome. This study revealed that the magnitude of intimate partner violence during their index pregnancy was $7.3 \%$. This is lower than

Table 3 Bivariate and multivariate logistic regression analyses of still birth by socio demographic variables, obstetrics related variables and intimate partner violence during pregnancy

\begin{tabular}{|c|c|c|c|c|c|}
\hline \multirow[t]{2}{*}{ Variables } & & \multicolumn{2}{|c|}{ Still birth } & \multirow[t]{2}{*}{$\operatorname{COR}(95 \% \mathrm{Cl})$} & \multirow[t]{2}{*}{$\mathrm{AOR}(95 \% \mathrm{Cl})$} \\
\hline & & Yes & No & & \\
\hline \multirow[t]{2}{*}{ Marital status } & Marriage & 20 & 590 & $.38(0.109-1.35)$ & \\
\hline & Single & 3 & 34 & $1: 00$ & \\
\hline \multirow[t]{2}{*}{ Resident } & Urban & 13 & 445 & $.52(0.22-1.2)$ & \\
\hline & Rural & 10 & 179 & $1: 00$ & \\
\hline \multirow[t]{2}{*}{ Religion } & Orthodox & 21 & 560 & $1.2(0.27-5.2)$ & \\
\hline & Muslim & 2 & 64 & $1: 00$ & \\
\hline \multirow[t]{3}{*}{ Age } & $>19$ & 4 & 46 & $1.37(.32-5.7)$ & \\
\hline & 20-35 & 15 & 515 & $.45(0.14-1.4)$ & \\
\hline & $>35$ & 4 & 63 & $1: 00$ & \\
\hline \multirow[t]{2}{*}{ IPV } & Yes & 6 & 41 & $5(1.87-13.4)$ & $3.3(1.1-9.7)$ \\
\hline & No & 17 & 583 & $1: 00$ & $1: 00$ \\
\hline \multirow[t]{2}{*}{ Hypertension } & Yes & 2 & 64 & $.83(0.19-3.6)$ & \\
\hline & No & 21 & 560 & $1: 00$ & \\
\hline \multirow[t]{2}{*}{$\mathrm{APH}$} & Yes & 3 & 32 & $2.77(0.78-9.8)$ & \\
\hline & No & 20 & 592 & $1: 00$ & \\
\hline \multirow[t]{2}{*}{ PROM } & Yes & 4 & 158 & $.62(0.2-1.8)$ & \\
\hline & No & 19 & 466 & $1: 00$ & \\
\hline \multirow{2}{*}{$\begin{array}{l}\text { Habit of } \\
\text { alcohol intake }\end{array}$} & Never & 13 & 346 & $1.04(0.45-2.4)$ & \\
\hline & Sometimes & 10 & 278 & $1: 00$ & \\
\hline \multirow{2}{*}{$\begin{array}{l}\text { Pregnancy } \\
\text { wanted }\end{array}$} & Yes & 19 & 586 & $1: 00$ & \\
\hline & No & 4 & 38 & $3.24(1.05-10)$ & $2.3(0.72-7.7)$ \\
\hline \multirow[t]{2}{*}{ ANC follow up } & Yes & 22 & 589 & $1.3(0.17-9.9)$ & \\
\hline & No & 1 & 35 & 1:00 & \\
\hline \multirow[t]{2}{*}{ Birth weight } & $>=2.5 \mathrm{~kg}$ & 5 & 522 & $1: 00$ & $1: 00$ \\
\hline & $<2.5 \mathrm{~kg}$ & 18 & 102 & $18.4(6.6-50.7)$ & $16.7(6-46)$ \\
\hline \multirow[t]{2}{*}{ Gestational age } & $>=37$ week & 13 & 564 & 1:00 & \\
\hline & $<37$ week & 10 & 60 & $7.23(3-17)$ & \\
\hline
\end{tabular}


study done in Tanzania (30\%), Vietnam (32.5\%) and Ethiopia hosanna $(23 \%)[7,14,17]$. These disparities in the reported prevalence rates might be attributed to study area and time differences. Most of the studies with higher prevalence were done many years ago and it is plausible that there has been some improvement in awareness about the dangers of IPV during pregnancy. However, it is also possible that there may be under reporting of IPV in our study population.

In this study the prevalence of still birth was found to be $3.6 \%$. Our finding is similar with the findings from Tanzania [18] and Zimbabwe [19] where 3.5 and 5.6\% of women had still birth respectively. But this study finding is significantly higher than that reported from central Vietnam $(0.97 \%)$ and the recommended goal of $1.2 \%$ by the 2014 newborn action plan.

$[9,20]$. This difference might be accounted by study area difference or difference in accessibility to prenatal or emergency obstetric care services.

This study found that IPV has significant association with still birth. This finding is in line with a research done in Columbia, South Carolina and California which indicated that women who experienced IPV during pregnancy have increased risk of still birth [21, 22]. IPV can lead to still birth either by direct (trauma) or indirect impact (such as decreased nutritional intake due to psychosocial trauma etc). In addition to this, women who experience sexual violence may be exposed to HIV and sexually transmitted diseases that can impact neonatal outcome. Finally, IPV can affect women's ability to access antenatal care.

In this study still birth has association with low birth weight. Babies delivered with low birth weight increased the risk of still birth by sixteen times. This finding is supported by research done in north Tanzania and periurban District in Ghana; being low birth weight increase the risk of still birth by more than nine times $[18,23]$. Fetus with low weight may have a high risk of death due to their immature respiratory system [18].

\section{Limitation of the study}

Since IPV during pregnancy is sensitive and selfreported, there is a risk of under reporting. Given that this is a cross-sectional rather than a prospective study, it is not possible to establish the temporal relation between IPV and stillbirth.

\section{Conclusion}

This study shows that still birth is high in this population and intimate partner violence during pregnancy has significant association with pregnancy outcome, namely still birth. It is important that healthcare providers involved in maternal care as well as the federal ministry of health prioritize formulating a protocol for screening intimate partner violence during pregnancy to reduce still birth.

\section{Abbreviations}

EDHS: Ethiopia Demographic Health Survey; IPV: Intimate Partner Violence; SGA: Small for Gestation Age; PROM: Premature Rapture of Membrane; ANC: Antenatal Care; APH: Antepartum Hemorrhage

\section{Acknowledgments}

We are very grateful to Mekelle University for the approval of the ethical clearance and for their technical and financial support of this study. We are grateful to the postpartum women who participated in this study, the hospital staff working in study area hospitals.

\section{Authors' contributions}

KG is participated in design proposal, monitoring during data collection, analysis and manuscript writing. GG, SW and MM also participated in reviewing the proposal, monitoring during data collection, analysis and review of the manuscript. All the authors have read and approved the manuscript.

\section{Authors' information's}

KG, SW, MM and GG Mekelle University College of Health Sciences, department of midwifery.

Funding

No funding.

\section{Availability of data and materials}

The data supporting the findings of this article can be provided if requested us.

\section{Ethics approval and consent to participate}

An ethical approval for the study was obtained from Mekelle University College of health science health research ethics review committee. Permission letter was obtained from regional health office and was presented to selected hospitals. Oral consent was taken from each participant before the start of data collection. Confidentiality was assured that their responses will not in any way be linked to them. In addition, they were told they have the right not to participate and withdraw from the study.

Consent for publication

Not applicable.

\section{Competing interests}

There is no competing of interest for this research.

Received: 21 March 2020 Accepted: 23 June 2020

Published online: 27 July 2020

\section{References}

1. Intimate Partner Violence: Definitions. November 252014 [cited, Http:// www.cdc.gov/violencepreven 2015 April 7]; Available from:, Tion/ intimatepartnerviolence/definitions.html. Intimate partner violence.

2. Women. VA. 2014Available from: Www.who.int/mediacentre/factsheets/fs23 9/en/.

3. Han A, Stewart DE. Maternal and fetal outcomes of intimate partner violence associated with pregnancy in the Latin American and Caribbean region. Int J Gynecol Obstet [Internet]. 2014;124(1):6-11 Available from: http://ovidsp.ovid.com/ovidweb.cgi?T=JS\&PAGE=reference\&D=emed12 \&NEWS $=\mathrm{N} \& A N=2013818897$.

4. Adhena G, Oljira L, Dessie Y, Hidru HD. Magnitude of intimate partner violence and associated factors among pregnant women in Ethiopia. Adv Public Heal. 2020;2020:1-9.

5. Bifftu BB, Dachew BA, Tadesse Tiruneh B, Zewoldie AZ. Domestic violence among pregnant mothers in Northwest Ethiopia: prevalence and associated factors. Adv Public Heal. 2017;2017:1-6.

6. Garcia-Moreno C, Jansen HA, Ellsberg MHL, CH W. Domestic violence against women study team. Prevalence of intimate partner violence: findings from the WHO multi-country study o women's health and domestic violence. Lancet. 2006;368:1260-9.

7. Laelago T, Belachew T, Tamrat M. Effect of intimate partner violence on birth outcomes. Afr Health Sci. 2017;17(3):681-9. 
8. Karen M Devries, Sunita Kishor HJ, 687 African Health Sciences Vol 17 Issue 3, September 2017, Heidi Stöckl, Loraine J Bacchus CG-M, Watts C. Intimate partner violence during pregnancy: analysis of prevalence data from 19 countries. Reprod Health Matters 2010;18(36):158-170.

9. Shamu S, Abrahams N, Temmerman M M, A ZC. Systematic Review of African Studies on Intimate Partner Violence against pregnant Women: Prevalence and Risk Factors. PLoS One. 2011;6(3):e17591.

10. Survey H. Ethiopia; 2016.

11. Blencowe H, Cousens S, Jassir FB, Say L, Chou D, Mathers C, et al. National, regional, and worldwide estimates of stillbirth rates in 2015, with trends from 2000: a systematic analysis. Lancet Glob Heal [Internet]. 2016;4(2):e98108 Available from: https://doi.org/10.1016/S2214-109X(15)00275-2.

12. Gazmararian JA, Lazorick S, Spitz AM, LE Ballard TJS, JS. M. Prevalence of violence against pregnant women. JAMA. 1996;275:1915-20.

13. Silverman JG, Decker MR, Reed ERA. Intimate partner violence around the time of pregnancy: association with breastfeeding behavior. J Womens Heal. 2006;15:934-40.

14. Hoang TN, Van TN, Gammeltoft T, Meyrowitsch DW, Thuy HNT, Rasch V. Association between intimate partner violence during pregnancy and adverse pregnancy outcomes in Vietnam: A prospective cohort study. PLoS One. 2016;11(9).

15. Janssen PA, Holt VL, Sugg NK, Emanuel I, Critchlow CM, Henderson AD. Intimate partner violence and adverse pregnancy outcomes : a populationbased study; 2003.

16. Yu H, Jiang X, Bao W, Xu G, Yang R, Shen M. Association of intimate partner violence during pregnancy, prenatal depression, and adverse birth outcomes in Wuhan. China BMC Pregnancy Childbirth. 2018;18(1):1-7.

17. Sigalla GN, Mushi D, Meyrowitsch DW, Manongi R, Rogathi JJ, Gammeltoft T, et al. Intimate partner violence during pregnancy and its association with preterm birth and low birth weight in Tanzania: a prospective cohort study. PLoS One. 2017;12(2):1-14.

18. Chuwa FS, Mwanamsangu AH, Brown BG. Mahande J. Maternal and fetal risk factors for stillbirth in Northern Tanzania : A registry-based retrospective cohort study. 2017:1-10.

19. Feresu SA, Harlow SD, Welch K, Gillespie BW. BMC pregnancy and childbirth incidence of stillbirth and perinatal mortality and their associated factors among women delivering at Harare maternity hospital. Zimbabwe : a crosssectional retrospective analysis. 2005;12:1-12.

20. Thi H, Giang N, Pozza SB. Tran HT. Stillbirth and preterm birth and associated factors in one of the largest cities in central Vietnam. 2018:1-7.

21. Coker AL, Sanderson M, Dong B. Partner violence during pregnancy and risk of adverse pregnancy outcomes. Paediatr Perinat Epidemiol. 2004;18(4):260-9.

22. El Kady D, Gilbert WM, Xing G, Smith LH. Maternal and neonatal outcomes of assaults during pregnancy. Obstet Gynecol. 2005;105(2):357-63.

23. A. Alhassan, L.A. Ayikai, H. Alidu VNY. Stillbirths and associated factors in a peri-urban district in Ghana. J Med Biomed Sci 2016;5(1):23-31.

\section{Publisher's Note}

Springer Nature remains neutral with regard to jurisdictional claims in published maps and institutional affiliations.

Ready to submit your research? Choose BMC and benefit from:

- fast, convenient online submission

- thorough peer review by experienced researchers in your field

- rapid publication on acceptance

- support for research data, including large and complex data types

- gold Open Access which fosters wider collaboration and increased citations

- maximum visibility for your research: over $100 \mathrm{M}$ website views per year

At BMC, research is always in progress.

Learn more biomedcentral.com/submissions 